\title{
VALOR E PLURALISMO MORAL
}

\author{
Flávia C. Chagas \\ UFPel \\ "Há quem passe pelo bosque e apenas veja \\ lenha para a fogueira" (Tolstói).
}

RESUMO: A ideia de que juízos de valor são subjetivos, sem garantias teóricas objetivas ou impossíveis de serem objeto de uma justificação racional, não é assunto novo, não apenas no ambiente filosófico, mas também no senso comum. Contra esta posição, pretendemos argumentar que não só é possível, mas que a justificação racional dos valores e regras morais é necessária e que um possível fio condutor para tal tarefa consiste no insight kantiano a partir do princípio de universalização. Além disso, procuramos mostrar que e como tal solução é compatível com o pluralismo moral sem cair em um relativismo moral.

ABSTRACT: The idea that judgments about values are subjective, without objective theoretical guarantees or which are impossible to have a rational justification, is not a new issue, not only in the philosophical area, but also on common sense. Against this position, we intend to argue that it is not only possible but that rational justification of moral values and rules is needed and that a possible common thread for this task consists in Kant's insight from the universal principle. Also, we try to show why and how such a solution is compatible with moral pluralism without falling into moral relativism.

A ideia de que juízos de valor são subjetivos, sem garantias teóricas objetivas ou impossíveis de serem objeto de uma justificação racional, não é assunto novo, não apenas no ambiente filosófico, mas também no senso comum. Com efeito, sem entrar na discussão sociológica, antropológica ou psicológica, ou seja, empírica acerca de se e como é possível justificar 


\section{Dossiê Naturalismo, Dissertatio - Volume Suplementar 02 I UFPel [2015}

moralmente nossas escolhas tendo em vista os possíveis fatores que condicionam (mas não determinam) as nossas ações, o ceticismo filosófico sustenta, de modo geral, que não é possível disputar sobre questões valorativas, de modo que questões sobre "o que é o bom?" ou "como nós devemos viver?" remetem apenas ao foro subjetivo de avaliação e decisão moral.

Como é bem conhecido, a perspectiva kantiana consiste em uma das posições que vai na contracorrente deste tipo de argumentação esboçada acima, na qual nós poderíamos incluir tanto perspectivas céticas como a do amoralista, por exemplo, quanto a de emotivistas, que rejeitam a possibilidade e mesma a necessidade de justificação de valores e normas morais.

Mas a tese de que a razão prática deve servir de fio condutor para a justificação de valores morais não se restringe ao escopo das éticas universalistas de caráter kantiano, mas é defendida entre perspectivas teóricas mais abrangentes, digamos assim, como é o caso do pragmatismo de Hilary Putnam ou do liberalismo social do filósofo e economista Amartya Sen. De fato, logo no início do seu livro "The Collapse of the Fact/ Value Dichotomy and Other Essays", Putnam afirma que "a ideia de que "juízos de valor são subjetivos" é uma criação da filosofia que veio a ser gradualmente aceita por muitas pessoas, como se fizesse parte do senso comum. Nas mãos de pensadores sofisticados, essa ideia pode ser, e foi, desenvolvida de diferentes maneiras. Tratarei daqueles que sustentam que os "enunciados de fato" são capazes de ser "objetivamente verdadeiros" assim como "objetivamente garantidos", enquanto os juízos de valor, segundo esses pensadores, são incapazes de verdade objetiva e de garantia objetiva. Segundo os mais extremados proponentes de uma nítida dicotomia entre fato e valor, os juízos de valor estão completamente fora da esfera da razão. Este livro tenta mostrar que, desde o início, estas visões baseiam-se em argumentos insustentáveis e em 
dicotomias superinflacionadas. Veremos que esses argumentos insustentáveis tiveram, no século XX, consequências importantes "no mundo real” (Putnam, 2008, p.13).

Com efeito, segundo ele, a ideia de que juízos de valor são apenas subjetivos e que, portanto, não podemos disputar racionalmente sobre eles, é fruto de determinadas histórias e construções filosóficas que tiveram seu início com o empirismo moderno, mas foram reafirmadas e consolidadas com o seu "rebento" do século XX, a saber, o positivismo lógico. Assim, um dos objetivos da análise de Putnam neste livro é mostrar que o porquê dos juízos de valor carecerem de objetividade deve-se aos defensores da dicotomia entre fato e valor, esta, por sua vez, atribuída ao conhecido argumento humeano de que de juízos sobre como o mundo é (enunciados descritivos sobre os fatos) não é possível inferir como o mundo deve ser (enunciados prescritivos sobre os valores). Mas tal distinção remete a uma outra, a saber, a distinção entre juízos sobre relações entre ideias ou analíticos e juízos sobre questões de fato e de existência ou sintéticos (a posterior), de modo que tais juízos sintetizam o conjunto de enunciados capazes de portar algum tipo de objetividade, pois o valor de verdade de tais enunciados depende ou simplesmente das relações lógicas entre os conceitos envolvidos ou da possibilidade de verificar a correspondência entre representação e objeto ${ }^{1}$.

${ }^{1}$ Putnam não rejeita a necessidade e a utilidade de se fazer a distinção entre fato e valor. 0 que muitos teóricos, entre eles, Putnam, Sen, Nagel, Hare, Habermas, Korsgaard rejeitam é a tese de que, para serem objetivos ou possuir algum tipo de pretensão de validade objetiva, os juízos devem ser descritivos. Com efeito, nesta direção, Cristine Korsgaard sustenta em seu artigo "Realismo e construtivismo na filosofia moral do século XX" que: "o importante para meus propósitos é que até mesmo quando dizemos que o elemento verificacionista foi extraído do verificacionismo - isto é, mesmo quando os filósofos reclamaram a inteligibilidade das proposições que não podem ser verificadas através das ciências empíricas - ainda assim um elemento foi mantido no quadro conceitual do modelo verificacionista. Esse elemento é a ideia de que é função de todos os nossos conceitos, ou de qualquer tipo de conceitos autenticamente cognitivos, descrever a realidade. Devemos prosseguir cautelosamente aqui. Ao levantar essa questão, não significa que pretendo negar a existência de um sentido em que todos os nossos conceitos - isto é, todos os conceitos que precisemos utilizar - possam ser utilizados 
Sem entrar nos pormenores das dificuldades entre as verdades por convenções e a crítica de Quine à dicotomia analítico/sintético, nem nos problemas das descrições definidas e da questão sobre a noção de verdade entendida como correspondência, é importante delimitar a nossa reconstrução do problema da justificação da ética, de modo a chamar a atenção apenas, neste momento da argumentação, para o fato de que não apenas tautologias ou verdades factuais/ empiricamente verificáveis podem reivindicar validade objetiva para os seus enunciados, mas também certos enunciados sobre valor moral; sem que seja necessário apelar para a problemática noção de fatos ou verdades morais, que precisariam ser, por assim dizer, descobertos.

em proposições que de fato descrevem a realidade, no sentido de que elas são capazes de ser verdadeiras ou falsas. Pelo contrário, quero questionar a ideia de que é para isso que servem todos os nossos conceitos, ou seja, que a sua função cognitiva é, por assim dizer, descrever a realidade. Enquanto mantivermos essa ideia, parecerá que o realismo moral é a única alternativa possível ao relativismo, ceticismo, subjetivismo e todas as outras formas nas quais a ética parece sem solução/incorrigivel. E enquanto o realismo moral for a única alternativa aparente para essas opções céticas, a necessidade de mostrar que a verdade moral é uma verdade sólida, real, objetiva e científica e, ainda, que ela é objetiva da mesma forma que uma verdade científica - parecerá urgente. Essa era a nossa situação até meados do século XX. Estou ciente de que o que eu disse sobre a função dos nossos conceitos parecerá vago até que eu articule uma função alternativa. Pretendo fazer isso agora, mas primeiro ressalto que, desde o começo, já existia um problema com a distinção entre ética cognitivista e não cognitivista. A distinção sugere que o julgamento moral se articula com a descrição de algum fato ou com uma versão dissimulada de um uso alternativo da linguagem - descritiva ou prescritiva. Mas qual o resultado disso para as teorias como de Aristóteles e de Kant, segundo as quais julgamentos morais são conclusões de um pensamento prático? Uma conclusão de um pensamento prático não é obviamente a descrição de um fato do mundo, mas ela também dificilmente se parece com algum tipo de expressão emocional. Onde se encaixam essas teorias então? Acredito que a resposta seja que elas não se encaixam, mas infelizmente isso parece não ser tão óbvio, já que a questão levanta outra pergunta sobre os princípios da própria razão prática. Nós podemos dizer que é verdade que uma ação é correta somente quando concorda com o imperativo categórico, por exemplo, mas o que dizer sobre o imperativo categórico em si? Quando perguntamos sobre o status dos princípios da razão prática, a questão do cognitivismo e do não cognitivismo parece se colocar mais uma vez. Poderíamos, por exemplo, supor que os princípios da razão prática são verdades autoevidentes conhecidas por intuição e, então, Kant apareceria como um racionalista realista tradicional. Isso não é apenas uma fantasia, de fato Kant foi lido dessa maneira por muitos filósofos do final do século XIX e do século XX, especialmente na Grã-Bretanha. Sidgwick e Mill, que o interpretaram dessa forma, servirão como exemplo suficiente. Alternativamente, alguém que toma seriamente a tese kantiana de que leis morais são as leis da autonomia, legisladas pela própria vontade do agente, pode lê-lo, como Hare parece fazer, como um prescritivista e, portanto, um não-cognitivista. Assim, embora teorias da razão práticas possam inicialmente parecer não se sustentar, existem formas de adaptá-las ao modelo". (Korsgaard, C., Realismo e construtivismo na Filosofia Moral do século XX. In: A Filosofia Prática de Kant: ensaios. Pelotas: Nepfil Online, 2014, p.25-26) 
Dizer que a ética filosófica não tem como função a de descrever fatos ou verdades morais, que poderiam, neste caso, ser objeto de uma descrição, implica a impossibilidade de disputar sobre questões valorativas? Ou ainda, a renúncia da objetividade na ética e em questões de valor se baseia no fato de que a ética não tem uma função descritiva? E, além disso, a solução é inevitavelmente o ceticismo em termos de valores?

Se entendermos que a tarefa da ética enquanto filosofia moral não é apenas, ou melhor, substancialmente, a de descrever o mundo, mas de pretender oferecer um guia possível para a conduta humana, ou seja, uma resposta à pergunta clássica sobre a vida boa, parece-nos impossível negar a possibilidade, e mesmo a necessidade, seguindo Kant e Putnam, de disputarmos não só sobre os meios, mas também sobre os fins quando tratamos acerca de questões valorativas. Todavia, esta disputa, segundo estes filósofos, depende e passa por encontrar uma noção de racionalidade aplicável às questões normativas ${ }^{2}$.

Tal noção de racionalidade deve ser capaz de garantir o pluralismo moral das várias concepções de bem sem cair, por um lado, em uma relativismo moral e, por outro, sem buscar uma fundamentação última para o moralmente bom entendido em termos de um realismo moral "forte", como é o caso, por exemplo, de Boyd e Railton, os quais defendem a ideia geral de que a objetividade na ética supõe a noção de objetividade análoga às ciências naturais (ou seja, de que há fatos morais que são válidos objetivamente ou independentes da mente).

Assim, o objetivo desta comunicação é tentar mostrar que e como a perspectiva kantiana é capaz de oferecer, senão a melhor, pelo menos, uma boa alternativa para a solução do problema em questão, a saber, encontrar e

\footnotetext{
${ }^{2}$ Isto sugere, de antemão, o ceticismo em relação ao conjunto de teorias que negam que a razão prática cumpra um papel fundamental na justificação moral, tais como as teorias expressivistas e nãocognitivistas atuais.
} 


\section{Dossiê Naturalismo, Dissertatio - Volume Suplementar 02 I UFPel [2015}

justificar uma noção de racionalidade prática capaz de garantir o pluralismo moral sem cair em um relativismo.

Apesar de serem bem conhecidas as críticas ao paradigma kantiano, eu gostaria de chamar a atenção para algumas que servirão de diálogo nesta comunicação, quais sejam: 1) a de que se trata de uma noção de racionalidade atemporal, descontextualizada, ahistórica ${ }^{3}$; 2) a ética kantiana é uma ética do 'dever pelo dever', o que significa dizer que se trata de uma ética rigorista, que exige demais do sujeito ${ }^{4}$; 3) se trata de uma ética que não contempla o pluralismo das concepções de bem ${ }^{5}$, já que a única ação capaz de ter valor moral é aquela que se funda no IC.

Contra estas objeções, tentarei mostrar que estas três críticas são injustificadas pelas seguintes razões que serão desenvolvidas ao londo deste texto, a saber: 1) a crítica de que se trata de uma noção de racionalidade descontextualizada e ahistórica depende de se assumir a teoria dos dois mundos, ou ainda, da sustentação de uma dupla ontologia para poder justificar tal concepção de razão prática; 2) Como afirmam Sen e Putnam, seria uma pressuposição muita rasa a respeito dos seres humanos identificar a escolha racional com a busca pela realização apenas do autointeresse, tendo em vista que o sujeito valoriza e tem razão para valorizar "coisas" como comprometimentos, ideais, valores, que não se esgotam na visão estreita da busca pelo prazer e a tendência a evitar a dor. Este ponto pode remeter também ao vínculo importante para Kant entre as noções de moralidade e

${ }^{3}$ Cf. por exemplo, Schopenhauer, A. Sobre o fundamento da Moral. São Paulo: Martins Fontes, 1995; Williams, B. Moral: Uma introdução à ética. São Paulo: Martins Fontes, 2005; Se, A. A ideia de Justiça. São Paulo: Companhia das Letras, 2011; Tugendhat, E. Lições sobre Ética. Petrópolis: Vozes, 2010; Kersting, W. Liberdade e Liberalismo. Porto Alegre: Edipucrs, 2005.

${ }^{4}$ Idem.

${ }^{5}$ Kekes, John. The morality of pluralism. Princenton University Press, 1993. Ver também a análise de Audi, R. Moral Knowledge. Oxford: Oxford University Press, 1997, p. 40-41. 
virtude; 3) por fim, a terceira crítica de que se trata de uma ética que falha a respeito de justificação do bom de modo tal que possa integrar diferentes concepções de bem. A proposta kantiana é justamente o contrário: de que só a partir de um critério formal de avaliação moral é possível garantir o pluralismo moral sem cair em um relativismo moral.

Para evitar mal entendidos, faz-se necessário chamar a atenção para o fato de que o objetivo deste paper consiste menos em uma defesa de Kant a partir da tentativa de refutação destas objeções, e sim investigar com um pouco mais de detalhe uma implicação, aparentemente bastante óbvia, da noção de razão prática como encontramos no paradigma kantiano mas que não têm sido, à primeira vista, tão aprofundada pelos comentadores, a saber, que, exatamente contra tais objeções, Kant defende o pluralismo das concepções de bem, de modo que tal tese só pode ser garantida a partir de uma concepção da racionalidade prática enquanto fundamento do valor moral das ações. Nesta perspectiva, lemos na Antropologia:

Finalmente, o egoísta moral é aquele que reduz todos os fins a si mesmo, que não vê utilidade senão naquilo que lhe serve, e também como eudemonista coloca simplesmente na utilidade e na própria felicidade, e não na representação do dever, o fundamento-dedeterminação supremo de sua vontade. Pois como cada ser humano forma conceitos diferentes sobre aquilo que considera fazer parte da felicidade, é precisamente o egoísmo que leva a não ter pedra de toque alguma do genuíno conceito do dever, que, como tal, tem de ser inteiramente um princípio de validade universal. - Todos os eudemonistas são, por isso, egoístas práticos. Ao egoísmo pode ser oposto apenas o pluralismo, isto é, o modo de pensar que consiste em não se considerar nem em proceder como se o mundo inteiro estivesse encerrado em seu próprio eu, mas como um simples cidadão do mundo» (Kant, Anthropologie, VI, BA 8).

Para entendermos como é possível esta ligação entre a noção da racionalidade prática enquanto núcleo do valor moral e como esta concepção permite Kant falar que o critério do imperativo categórico é o que justamente 


\section{Dossiê Naturalismo, Dissertatio - Volume Suplementar 02 I UFPel [2015}

torna possível o pluralismo moral, nós vamos, primeiramente, investigar as exigências e pressupostos da compreensão kantiana de agência prática para ver se e como é possível dizer que esta possibilita o pluralismo moral.

\section{Racionalidade Prática e Valor Moral}

Para entendermos a tese kantiana de que o valor moral de uma ação depende de que esta se baseie na exigência normativa de racionalidade prática, duas considerações são indispensáveis:

1) é a racionalidade prática, em seu aspecto formal, a fonte do valor moral;

2) para concebermos esta exigência, que reúne aspectos de ética normativa ou substantiva, nós não precisamos supor ontologias super-inflacionadas, ou seja, como afirma Putnam, estórias metafísicas, mesmo a partir do texto kantiano.

Em relação ao primeiro ponto, Kant esclarece o que ele entende pela forma da lei enquanto um fundamento de determinação da vontade nas primeiras duas Seções da GMS e nos seis primeiros parágrafos da KpV a partir da distinção entre agir de acordo com máximas que podem ser consideradas válidas apenas subjetivamente ou objetivamente. Este modo de ajuizamento, segundo ele, só é possível pela disposição que o sujeito tem de agir com base na representação de regras.

Nestes dois textos mencionados acima, a saber, a $G M S^{6}$ e a $K p V$

${ }^{6}$ Kant, I. Werke in Sechs Bänden. Herausgegeben von Wilhelm Weischedel. Wiesbaden: Insel Verlag, 
lemos que o imperativo categórico consiste, então, não em uma norma concreta ou conjunto de normas concretas, mas um critério formal de avaliação de máximas. Logo, não está dado a priori quais máximas são ou não morais, de modo que cabe ao sujeito avaliar, a partir da sua consciência moral, quais máximas poderiam ser pensadas como válidas de uma perspectiva universal.

Não obstante Kant deixe claro que o imperativo categórico não consiste em um conjunto de normas empíricas ou mesmo uma verdade moral, é importante chamar a atenção para o fato de que este é um dos pontos de grandes confusões na exegese do texto kantiano, pois enquanto muitos acusam Kant de defender um universalismo cosmopolita ou uma metafísica realista no sentido de defender a existência de fatos morais que poderiam ser intuídos por uma intuição intelectual, nós devemos lembrar ao leitor desavisado duas teses centrais do projeto crítico-transcendental, que são: 1) o limite de todo o possível conhecimento - nós só podemos conhecer aquilo que puder ser objeto de uma intuição espaço-temporal - e 2) o imperativo categórico consiste em um princípio formal de avaliação de máximas ou de princípios subjetivos.

Em resumo, podemos dizer: se as regras são representadas como boas apenas subjetivamente, ou seja, consideradas válidas apenas para a 'minha' vontade, então o fundamento de determinação do arbítrio consiste na expectativa das sensações de prazer decorrentes da realização de algum objeto apetecido. Portanto, tais máximas não podem pretender ter validade universal, ou seja, serem consideradas como boas moralmente. Todavia, tendo em vista que o bom não se confunde nem com o útil, nem com o agradável, máximas erguem a pretensão de serem consideradas como morais se elas podem ser consideradas como válidas para todo ser racional em geral a partir do critério

2011. Doravante utilizarei as siglas usuais para citar as obras de Kant: Crítica da Razão Prática (KpV), Crítica da Razão Pura (KrV), Fundamentação da Metafísica dos Costumes (GMS), Metafísica dos Costumes (MS). 
da universalizabilidade dos princípios subjetivos da vontade. A partir disso, surgem duas perguntas, quais sejam: 1) como eu posso saber se a máxima que "eu" considero como boa pode ser avaliada como válida para "nós" ou “todos"?, 2) como é possível que um ser como o homem pode querer agir de acordo com tais máximas morais abdicando da pretensão em satisfazer as suas inclinações e interesses particulares? Esta discussão nos remete ao tema do pluralismo moral. Antes disso, eu gostaria de fazer um breve comentário acerca do segundo ponto levantado acima.

A questão sobre quem é o sujeito moral em Kant, ou melhor, se está implícita uma dupla ontologia na justificação da sua concepção de razão prática é uma das questões mais controversas e difíceis de resolver "dentro" e fora da filosofia kantiana, de modo que um caminho promissor consiste em assumir a tese da $\mathrm{KrV}$ de que tudo aquilo que "existe" pode ser objeto de um possível conhecimento. Logo, Kant não precisa sustentar a realidade de um eu noumênico, suprassensível para fundamentar a validade do princípio moral, mas supor como ponto de partida para esta tarefa a consciência "moral" (prática) pré-filosófica do sujeito empírico na medida em que ele é capaz de agir a partir da representação de regras ${ }^{7}$. Ou seja, Kant não assume uma dupla

\footnotetext{
${ }^{7} \mathrm{Cf}$. as seguintes passagens que corroboram esta interpretação: GMS, 412, KpV, A 14 (nota), KpV, A 19 , etc. Além destas passagens, o $\S 6$ da $K p V$ (A 53) pode ser uma pista promissora de interpretação, em que Kant afirma, em analogia com a filosofia teórica, como nós podemos compreender a necessidade com que se impõe a consciência moral no momento em que 0 sujeito avalia as suas máximas. De fato, a premissa fundamental da ética kantiana é a de que a consciência moral se impõe a priori ou de modo necessário e constitui uma forma de autocompreensão, que não se confunde com nenhuma intuição intelectual, por um lado, e também, por outro, não pode ser resumida na mera consciência empírica de deveres morais. Assim, a consciência que o sujeito tem do que ele deve fazer em uma determinada situação pressupõe não apenas a autoconsciência prática da própria liberdade (Willkür), mas também o reconhecimento a priori da sua capacidade prática autorreflexiva (Autonomie). Em suma, 0 agente que reconhece que deve fazer $X$ ou que é moralmente necessário algo em uma determinada situação, aprova imediata e originariamente a validade da moralidade; logo, parece descabida ou sem sentido a pergunta, neste momento, como posso saber que tal consciência é real ou não?; ou ainda, a constatação de que além da consciência da necessidade de fazer $\mathrm{X}$ ainda preciso de algum tipo de intuição ou garantia teórica de que tal representação não é uma fantasia da imaginação. Isso significa, então, que antes da tematização do conteúdo do princípio moral, entendido como o imperativo categórico, nós temos que pressupor que todo ser racional humano reconhece
} 
ontologia com a distinção entre as duas perspectivas que o homem pode representar a si mesmo, como racional e sensível; trata-se, como afirma Kant, de uma distinção epistemológica entre diferentes pontos de vista que o mesmo sujeito pode considerar a si mesmo.

Pressupor que se trata de uma distinção 'real' é fazer aquilo que Ryle chama de um erro categorial. Com efeito, em "The concept of mind", Ryle afirma que o mito dos dois mundos trouxe, na verdade, mais prejuízos do que benefícios para entendermos do que se trata aqui com a distinção entre o mental e o físico.

Assim, se a suposição de que o ponto de partida do argumento de Kant consiste em assumir que a justificação da validade da consciência da lei moral enquanto um imperativo categórico baseia-se na consciência empírica que um agente tem, no momento em que ele ajuíza sobre o conteúdo de suas máximas, de uma exigência ou constrangimento a priori da razão prática, então nós não precisamos nos comprometer com a sustentação de teses metafísicas inflacionadas.

Por último, cabe lembrar que para Kant, não é possível formular máximas morais independentemente da mente humana. Ou seja, a consciência moral, ou a consciência do que eu devo fazer, só se apresenta quando o sujeito avalia as suas máximas; em outras palavras, só surge a partir da reflexão no ato de julgar as suas máximas. Por isso, uma criança que ainda não é capaz de julgar por conceitos, também seria incapaz de ter consciência do que deve fazer. Para concluir a resposta kantiana, realismo e idealismo estão entrelaçados no sistema crítico-transcendental. Logo, a realidade depende da percepção humana (o modo como a realidade é e deve-ser depende da perspectiva - do aparato cognitivo - humana).

originariamente, isto é, a priori, deveres morais, os quais não se confundem com as normas jurídicas, regras e padrões sociais de uma determinada sociedade ou cultura.

${ }^{8}$ Ryle, G. The Concept of Mind. Hertford College, University of Oxford, 2009. 


\section{Dossiê Naturalismo, Dissertatio - Volume Suplementar 02 I UFPel [2015}

Em seu livro sobre a "dicotomia entre fato/valor", Putnam segue a argumentação kantiana de que tanto as nossas descrições quanto as nossas valorações são dependentes do modo como nós "construímos" os nossos valores e crenças a partir da estrutura cognitiva da mente humana, ou seja, tais modos de "ver" (descrever/valorar) já supõem a priori uma perspectiva, um ponto de vista, em uma palavra, algum lugar.

Voltando ao primeiro ponto, se uma ação moral é aquela que satisfaz à exigência do critério da universalizabilidade das máximas da vontade, quais ações podem ser consideradas boas? Ou ainda, como eu posso saber que máximas são universalizáveis?

É importante lembrar que não há como definir, a priori, o que pode ser dito como uma máxima moral. Ou seja, Kant não pretende determinar, a partir do critério da universalizabilidade das máximas da vontade, um conjunto de 'verdades' ou 'normas' morais, as quais poderiam ser concebidas consensualmente como boas para guiar as ações. De fato, a ética kantiana não define o que exatamente deve ser considerado como moralmente bom. Assim, na medida em que o imperativo categórico não designa um conjunto de regras, mas um critério para a avaliação de regras, cabendo ao agente avaliar à luz do critério formal de racionalidade prática o que ele deve fazer, de modo que "a coisa certa a ser feita" implica o reconhecimento recíproco do outro como digno de respeito em sua autonomia e liberdade.

Assim, se não está pré-determinado quais máximas são morais ou que regras devem ser satisfeitas e, ou ainda, dizer que cada sujeito deve julgar a partir da sua consciência o que deve ser feito, não desencadearia em uma posição relativista, algo que Kant decisivamente não estaria disposto a aceitar em seu projeto de justificação da ética?

\section{Pluralismo social e pluralismo moral}


Para evitar mal-entendidos, eu gostaria de diferenciar aquilo que Barbara Herman chama de pluralismo social no segundo Capítulo do livro "Moral Literacy", como "a presença em uma sociedade de tradições distintas e modos de vida" ${ }^{10}$, e o pluralismo moral ou normativo que parece estar vinculado a uma exigência conceitual (ou metaconceitual) que busca justificar um conceito do moralmente bom sem supor a existência de fatos ou verdades morais.

Barbara Herman aponta para o fato de que em muitas perspectivas morais o pluralismo é visto como um fator potencial para não se conseguir resolver problemas de desacordo moral, o que requereria, então, a possibilidade de justificação de um valor ou norma objetivamente válida. Talvez seja este exatamente uma das razões de porque Kant é visto como opositor do pluralismo, a saber, por fundamentar a moralidade em um "único" princípio. Todavia, o que tentarei defender, como a Herman o faz, "uma das razões para abraçar um modelo kantiano de julgamento moral é que ele pode reconhecer as reivindicações distintas de valores locais sem considerá-las como fixas" (Herman, 2007, p.33).

O que parece problemático, todavia, na interpretação de Herman é que tal discussão sobre o pluralismo parece não ser solucionado com o que ela entende como pluralismo social. Minha conjectura é que neste ponto sistemático da argumentação Kant parece reivindicar algo 'mais forte', digamos assim, a saber, um pluralismo moral ou normativo, o que implica uma questão de justificação de segunda ordem.

Embora Barbara Herman trate dos "princípios práticos que

\footnotetext{
${ }^{9}$ Herman, B. Moral Literacy. Harvard University Press, 2007.

10 Herman, B; op. cit, p. 29, tradução minha. Esta concepção do pluralismo social em Herman não parece estar distante do que Rainer Forst determina como o contexto ético de justificação normativa em seu livro "Contextos da Justiça".
} 


\section{Dossiê Naturalismo, Dissertatio - Volume Suplementar 02 I UFPel [2015}

estruturam o domínio deliberativo" (Herman, 2007, p. 42), a discussão neste momento da sua argumentação parece estar muito mais centrada em como tais princípios podem ser experienciados na nossa sensibilidade moral, bem como na exigência de articulação com a socialização e educação dos indivíduos do que uma investigação sobre a justificação acerca do escopo da razão prática.

Todavia, Herman pretende mostrar, a partir da investigação sobre a natureza da agência racional em Kant, como o modelo kantiano, ao contrário do que os céticos objetam, pode servir de base para uma concepção pluralista dos diferentes modos de vida em uma mesma comunidade moral. Assim, se o pluralismo social diz respeito aos diferentes ethos em uma mesma comunidade (ou diferentes ethos em diferentes comunidades) em que nós podemos nos aproximar de um ponto de vista meramente descritivo, o pluralismo moral ou normativo está atrelado à tentativa de justificação de uma concepção de valor moral capaz de tentar refutar o relativismo moral.

Dito de outro modo, parece-nos que o problema em "ficar" apenas no nível de discussão do pluralismo social é que nós não teríamos como justificar porque algumas concepções de bem em algumas comunidades morais são problemáticas; o que demanda, então, um princípio normativo que seja capaz de mostrar que e porque certas concepções de bem não podem ser justificáveis.

Se nós voltamos ao sentido originário do princípio de universalização, vemos que este não deve ser entendido como uma verdade moral ou como o conteúdo verdadeiro da ética, mas sim no sentido de que ele indica um critério negativo, ou ainda, um conceito-limite que serve para "verificar" a possibilidade de coexistência de diferentes concepções de bem em uma sociedade democrática de direitos. Nesta perspectiva, não está dada de antemão quais devem ser os fins a serem buscados ou quais são as concepções de bem e os valores que detém um conteúdo moral, de fato, garantido, assim, 
o pluralismo social. Por outro lado, qualquer possível concepção de bem deve poder ser compatível com outras visões de mundo do ponto de vista da sua possibilidade de justificação racional.

A partir desta via de interpretação do critério moral kantiano, é possível justificar porque determinados valores de uma comunidade, como a prática de estupro corretivo ou mutilação de mulheres, ou também, como aponta Herman, desejos sádicos como abusar sexualmente de uma pessoa não poderiam ser justificadas como "boas" do ponto de vista moral, justamente porque ou elas lesam determinados direitos, ou não respeitam a pessoa em sua autonomia, ou estão fundados em um absurdo egoísmo, enfim, não poderiam ser racionalmente justificáveis perante a comunidade de seres humanos, para usar um termo de Rainer Forst no contexto de justificação normativo da moralidade em seu livro "Contextos de Justiça"11.

Mas aqui nós entramos em outro problema, que constitui uma das objeções citadas no início do texto, a saber, a justificação kantiana da tese de que o valor moral baseia-se na razão prática. Ou seja, afinal de contas: por que eu devo agir pela exigência normativa da racionalidade prática entendida a partir do critério da universalização? E, além disso, se tal exigência não está além dos interesses e do conjunto motivacional que o ser humano é capaz de ter? Embora seja a fonte de debates e diferentes interpretações, parece-nos que este não é meramente um problema de motivação e psicologia moral, mas de justificação e filosofia moral.

Para concluir, eu gostaria de chamar a atenção não tanto para a autocontradição prática que o sujeito que não quer se engajar em um tipo de agir que envolve certas capacidades como a disposição para agir com base em razões e justificá-las também a partir de razões, mas para alguns insights que

11 Forst, R. Kontexte der Gerechtigkeit, Politishe Philosophie jenseits von Liberalismus und Kommunitarismus. Frankfurt am Main, Suhrkamp, 1994. Contextos da justiça. Filosofia política para além de liberalismo e comunitarismo.Tradução de Denilson Luis Werle. São Paulo: Boitempo, 2010. 


\section{Dossiê Naturalismo, Dissertatio - Volume Suplementar 02 | UFPel [2015}

estão também no corpus kantiano, mas também encontram-se em diferentes tradições filosóficas:

1) um sujeito que não se pergunta "como ele deve gastar o tempo de sua existência" (Habermas, Sartre) é um sujeito que parece estar em algum sentido alienado;

2) tal como Sen, Nagel, Putnam apontam, o ser humano não define a sua vida pela busca incessante de sentir prazer e realizar apenas o seu próprio interesse; mas ele valoriza diferentes coisas que ele tem razão para valorizar, tais como caráter, valores, comprometimentos, causas ou ideais, relações e vínculos afetivos, etc;

3) Nós sempre podemos perguntar, como sugerem Forst, Korsgaard e Putnam, se aquilo que é visto como algo valoroso é, de fato, valioso. Para tanto, não precisamos de estórias metafísicas, mas da capacidade crítica que todos nós já compreendemos a partir das nossas práticas enquanto sujeitos inscritos em determinadas tradições, bem situados em diferentes contextos normativos.

Todavia, por fim, o quanto tais perguntas sobre a dita exigência normativa é capaz de servir de fio condutor das nossas vidas, isso é o que nós podemos dizer que já não é uma tarefa propriamente filosófica, mas que compete ao foro íntimo de cada um, e aqui vemos, o limite de toda investigação moral.

\section{REFERÊNCIAS}

AUDI, R. Moral Knowledge. Oxford: Oxford University Press, 1997.

FORST, R. Kontexte der Gerechtigkeit, Politishe Pbilosophie jenseits von Liberalismus und Kommunitarismus. Frankfurt am Main, Suhrkamp, 1994. Contextos da justiça. Filosofia política para além de liberalismo e comunitarismo. Tradução 
de Denilson Luis Werle. São Paulo: Boitempo, 2010.

HERMAN, B. Moral Literacy. Harvard University Press, 2007.

KANT, I. Werke in Sechs Bänden. Herausgegeben von Wilhelm Weischedel.

Wiesbaden: Insel Verlag, 2011.

KEKES, J. The morality of pluralism. Princenton University Press, 1993.

KERSTING, W. Liberdade e Liberalismo. Porto Alegre: Edipucrs, 2005.

KORSGAARD, C., 'Realismo e construtivismo na Filosofia Moral do século XX'. In: A Filosofia Prática de Kant. ensaios. Pelotas: Nepfil Online, 2014.

RYLE, G. The Concept of Mind. Hertford College, University of Oxford, 2009.

SCHOPENHAUER, A. Sobre o fundamento da Moral. São Paulo: Martins Fontes, 1995.

SEN, A. A ideia de Justiça. São Paulo: Companhia das Letras, 2011.

TUGENDHAT, E. Lições sobre Ética. Petrópolis: Vozes, 2010.

WILLIAMS, B. Moral: Uma introdução à ética. São Paulo: Martins Fontes, 2005. 